\title{
Greek Secondary School Pupils' Perceived Reasons for Behaving Appropriately and Perceived Teachers' Strategies to Maintain Discipline
}

\author{
KATERINA ZOUNHIA, DIMITRIS HATZIHARISTOS \& KOSTAS \\ EMMANOUEL, Department of Physical Education \& Sport Science, \\ National and Kapodistrian University of Athens, Greece
}

\begin{abstract}
The purpose of this study was to explore the reasons for pupils behaving appropriately in class, in several subjects of the school curriculum, and perceived teachers' strategies to maintain discipline. One hundred and forty-five pupils, aged 13-15 years, responded to questionnaires about reasons for behaving appropriately and their perceptions of strategies used by their teachers to maintain discipline. The present study is an extension of Papaioannou's (1998) study. The results indicated that in all subjects of school curriculum the reasons for pupils being well-behaved are mainly self-determined. In computer science, physical education, mathematics and the Greek language, pupils adopt significantly more self-determined reasons for behaving appropriately than in foreign languages, physics and religious education. Despite the differences among teachers' specialties, in order to maintain discipline teachers usually employ strategies that emphasise intrinsic reasons for discipline. In all school subjects there is a strong correlation between reasons for pupils' good behaviour and their perceptions about strategies used by their teachers to maintain discipline.
\end{abstract}

\section{Introduction}

One of the most important pedagogical issues that concern teachers is classroom discipline (McKinley \& Merrit, 1985; Guernsey \& Peary, 1986; Pieron, 1988; Harrison et al., 1996; Henkel, 1991; Graham, 1992; Lavay et al., 1997; Kiridis, 1999; Mieszalski, 1997; Robertson, 1998). According to several studies the majority of teachers believe that a well-behaved class is one of the most important indications of successful teaching (Placek \& Dodds, 1988; Parker, 1995).

Researchers that work on causes of discipline problems found that the reproductive [1] and authoritarian [2] character of Greek educational system causes serious discipline problems (Matsagouras, 1999a, 1999b). Another category of causes relates to the personality of the teacher and his/her organisation of the instructional procedure (Aravanis, 1998; Matsagouras, 1988; Papaioannou et al., 
1999). Besides the school environment the problem of discipline also directly relates to the family and social environment of a pupil (Aravanis, 1998; Matsagouras, 1988).

The issue of discipline is approached by several researchers based on pedagogical, psychological and social theories (Lavay et al., 1997; Papaioannou, 1998; Papaioannou et al., 1999; Kiridis; 1999). Many researchers associate the issue of discipline with the interest and motivation for learning (Harrison et al., 1996; Hellison, 1985, 1995 ; Hellison \& Templin, 1991; Miller, 1995; Erb, 1996; Papaioannou, 1998).

Papaioannou (1998) studied the field of student discipline in physical education, based on the cognitive evaluation theory (CET) and Hellison's responsibility model. CET is a theory with respect to the construct of intrinsic motivation. Intrinsic motivation takes place when people are totally self-determined and engaged in an activity purely for the pleasure derived from doing it (self-determined behaviour). Extrinsic motivation occurs when people feel less self-determined (controlled behaviour) (Deci \& Ryan, 1985, 1991; Ryan \& Conell, 1989). 'In general, research has shown that self-determined behaviours are of higher quality and have more positive correlates than controlled behaviours' (Deci \& Ryan 1994, pp. 4-5).

According to Deci \& Ryan (1991), people's reasons for acting can vary from being very external (e.g. 'I do it because others make me') to being intrinsic (e.g. 'I do it because it's fun'). They also suggested 'the regulation of actions can be viewed as being self-determined, controlled, or amotivated. Both self-determined and controlled behaviours are intentional, though only self-determined behaviours involve a true sense of choice, a sense of feeling free in doing what one has chosen to do. ... Amotivation with respect to an action refers to the person's being ineffective in regulating it' (Deci \& Ryan, 1991, p. 251). CET postulates that the behaviours of people are regulated by the following reasons: Intrinsic-intrinsically motivated behaviour reflecting fun, enjoyment, satisfaction or excitement while people perform an activity. External-refer to behaviour shaped by external rewards or to avoid punishment. Introjected-comprise internal pressures to act in order to avoid negative feelings such as guilt and shame. Identified-actions determined by personal values and goals (e.g. being physically active to assist health or prevent disease) (Papaioannou, 1998).

Hellison's responsibility model (Hellison, 1985, 1995; Hellison \& Templin, 1991) is a system of strategies in the context of physical education helping students to become more self-controlled. Hellison suggested the following five developmental levels for students to develop self-responsibility for their behaviour: Level 0 : irresponsibility; Level 1: self-control; Level 2: involvement; Level 3: self-responsibility; Level 4: caring. According to Papaioannou (1998), Hellison's responsibility model in the context of physical education has similarities to the classification of reasons for behaviours outlined by CET. He also adds that 'self-responsibility and caring reasons for behaving appropriately reflect humanistic values for acting and should be considered as identified according to CET' (p. 424).

Ryan and Conell (1989), in one of their studies, asked children to endorse the salience of external, introjected, identified, and intrinsic reasons for doing their schoolwork. The data confirmed that the four regulatory styles can be ordered along a single dimension of self-determination or autonomy. They also found that the more autonomous styles (identification and intrinsic) were positively correlated with enjoyment of school, expenditure of effort, proactive coping, and perception of classroom context as being autonomy supportive, while the less autonomous styles were correlated with anxiety and poor coping. 
Papaioannou (1998), based on the earlier mentioned theories, categorised the reasons for pupils behaving appropriately into six categories: (1) intrinsic reasons; (2) external reasons; (3) introjected reasons; (4) responsibility reasons; (5) caring reasons; (6) no reasons. The earlier researcher examined the relationship of: reasons for behaving appropriately, perceived teaching strategies aimed at maintaining discipline, goal orientations, and perceived motivational climate and found that teachers who try to strengthen the task orientation of pupils and help them adopt more self-determined reasons for behaving appropriately will have more orderly classes. A similar research has been done by Spray (2001) for English pupils and found, besides other findings, that task-involved children are more likely to possess self-determined reasons for appropriate conduct in physical education.

Regarding the strategies teachers use to face disciplinary problems, it was found, based on the literature of the subject, that there are two categories of strategies. The first category refers to strategies based on the notion that teachers can maintain order in the class by rewarding appropriate behaviours and preventing or punishing misbehaviours (Graham, 1992; Matsagouras, 1988, 1999b; Caffyn, 1989; Siedentop, 1995; Wan \& Salili, 1996; Lavay et al., 1997; Lu, 1997; Miller et al., 1998; Tulley \& Chiu, 1998; Kiridis, 1999). According to CET, these strategies promote external reasons for behaving appropriately in the class. The second category refers to strategies that help children take responsibility for their own behaviour-in other words to increase their self-determination. (Lavay et al., 1997; Hellison, 1985, 1995; Hellison \& Templin, 1991).

Papaioannou (1998) and Spray (2001) found that task-involved children perceive the physical education teacher to cultivate self-determined reasons for maintaining discipline in lessons, whereas teacher-emphasised introjected reasons are less salient.

The purpose of the present study was to extend the investigation of the reasons for pupils behaving appropriately, and the perceived strategies used by teachers to maintain discipline in several subjects of the secondary school. The study was designed to answer the following research questions: (a) Are there differences among several subjects of the curriculum in pupils' perceived reasons for behaving appropriately, and in perceived strategies used by teachers to maintain discipline? (b) For what reasons do the pupils behave appropriately in several subjects of the curriculum and what strategies are used by their teachers to maintain discipline, as perceived by pupils? and (c) Is there a relationship between pupils' reasons for behaving appropriately and their perceptions of teaching strategies used by their teachers to maintain discipline?

\section{Methodology}

\section{Sample}

A sample of 145 pupils (68 males, 77 females), aged 13-15 years, from 29 Greek secondary schools in the Prefecture of Athens were selected at random, using multistage cluster sampling, to participate in this study. First, one class of every school was selected. Then five pupils from those classes were selected. The pupils who participated in this study completed questionnaires about the reasons for behaving appropriately and perceived teachers' strategies to maintain discipline. Thus, questionnaires were obtained on 29 physical educators, 29 Greek language teachers (philologists), 29 mathematics teachers, 29 physicists, 29 teachers of foreign 
languages, 29 theologists and 26 teachers of computer science. In total, the pupils answered questionnaires concerning 200 teachers. The study had the permission of the Greek Ministry of Education and the school authorities.

\section{Questionnaires}

As mentioned earlier, the 145 pupils completed questionnaires about the reasons for behaving appropriately in several subjects of the school programme, and perceived teachers' strategies to maintain discipline. The questionnaires were developed by Papaioannou (1998) and are the following:

(a) Reasons for Discipline Scale (RDS). This questionnaire measures pupils reasons for behaving appropriately. The questionnaire includes 25 questions. Every pupil completed one questionnaire per teaching subject. The stem for all questions was 'When I am well-behaved in this class, it is because ...' Pupils were asked to indicate their responses on a five-point Likert-type scale $(1=$ strongly disagree, $5=$ strongly agree). For each subject of the school programme there was a separate questionnaire with the same questions. Eight questions of the questionnaire were used to assess intrinsic reasons for exercising discipline in class (e.g. 'the lesson is exciting') (question 8-15) and the reliability alpha Cronbach for these questions was 0.86 . Four questions were used to assess external reasons for exercising discipline in class (e.g. 'so others won't get nervous with me') (question 1-4) for which alpha Cronbach was estimated to 0.79. Pupils responded to three questions denoting introjected reasons for behaving appropriately (e.g. 'I will feel ashamed if I don't') (question 5-7) and the reliability alpha Cronbach was 0.87 . Four questions were used to assess self-responsibility reasons for behaving appropriately (e.g. 'I feel that I am responsible for what I learn') (question 19-22) for which alpha Cronbach was 0.84. Three questions were used expressing caring reasons for behaving appropriately (e.g. 'It's important for me that everybody in the class improves') (question 23-25) and the reliability alpha Cronbach was 0.83 . Finally pupils responded to three questions suggesting no reasons for behaving appropriately (e.g. 'I don't see why I should be disciplined') (question 16-18) and the reliability alpha Cronbach was 0.79.

(b) Strategies to Maintain Discipline Scale (SSDS). This questionnaire includes 25 questions measuring pupils' perceptions of strategies used by their teacher to maintain discipline in the class. Every pupil completed one questionnaire per teaching subject. The stem for all questions was 'The teacher in order to sustain discipline in this class ...' and responses were indicated on a five-point Likerttype scale $(1=$ strongly disagree, $5=$ strongly agree). For each subject of the school curriculum, there was a separate questionnaire, with the same questions. Fourteen questions of the questionnaire were used to assess teaching strategies emphasising intrinsic reasons for discipline (e.g. 'makes the lesson funny') (question 9-15 and 19-25) and the reliability alpha Cronbach for these questions was 0.94 . Four questions were used to assess teaching strategies emphasising introjected reasons for discipline (e.g. 'makes us feel bad about ourselves if we are not well-behaved') (question 5-8) for which alpha Cronbach was 0.83. Three questions were used to assess no strategy to maintain discipline (e.g. 'really does nothing to keep discipline') (question 16-18) and the reliability alpha Cronbach was 0.81 . Finally, four questions were used to assess teaching strategies empha- 
sising external reasons for discipline (e.g. 'reminds us that is the rule') (question 1-4) for which alpha Cronbach was 0.78 .

\section{Procedure}

The authors of this research visited the schools and asked the pupils to complete the above-mentioned anonymous questionnaires. Pupils were free to ask the researcher any questions. Pupils who wanted to ask questions could raise their hand and communicate privately with the researcher. Generally, completion of these questionnaires required about 40 minutes.

\section{Data analysis}

The primary source of the data was the answer on each item of the questionnaires. Following this, in every school subject the mean score was computed for each reason and each strategy. The differences among six reasons for pupils behaving appropriately and four perceived strategies used by their teachers to maintain discipline were examined separately for each school subject, using repeated measures analysis of variance. Repeated measures analysis of variance were also used to determine the differences among several school subjects for each reason for pupils behaving appropriately, and each perceived strategy used by their teachers to maintain discipline.

The repeated measures analysis of variance design was selected to analyse the data of this study because in every school subject every pupil evaluated the reasons for behaving appropriately and strategies used by the teachers to maintain discipline.

Pearson correlation analysis was conducted separately for each school subject to determine relationship between the reasons for behaving appropriately and each perceived strategy to maintain discipline.

\section{Results and Discussion}

The means $(M)$, standard deviations (SD) and $F$ values for each reason for behaving appropriately are presented in Table I. As shown in Table I, significant difference was found among several subjects of the curriculum on the intrinsic reasons $F$ (6, $115)=5.39, p<0.001$. The least-significant difference (LSD) pair-wise comparisons indicated that the pupils in computer science and physical education are significantly more intrinsically disciplined than in foreign languages, physics, and religious education. In mathematics and Greek language, pupils are significantly more intrinsically disciplined than in foreign languages and physics. For the rest of the reasons (responsibility, caring, introjected, external, no reason), statistically significant differences were not found.

The means, standard deviations and $F$ values for each perceived strategy used by teachers are presented in Table II. As shown in Table II, significant differences in the means existed in all strategies. A significant difference was found among several subjects of the curriculum on the strategies emphasising intrinsic reasons to maintain discipline. $F(6,116)=4.36, p<0.001$. Using LSD pair wise comparisons, it was found that in foreign languages and physics, according to the pupils' opinion, teachers emphasise significantly less intrinsic reasons to maintain discipline than do the teachers in religious education, in Greek language and physical education. A 


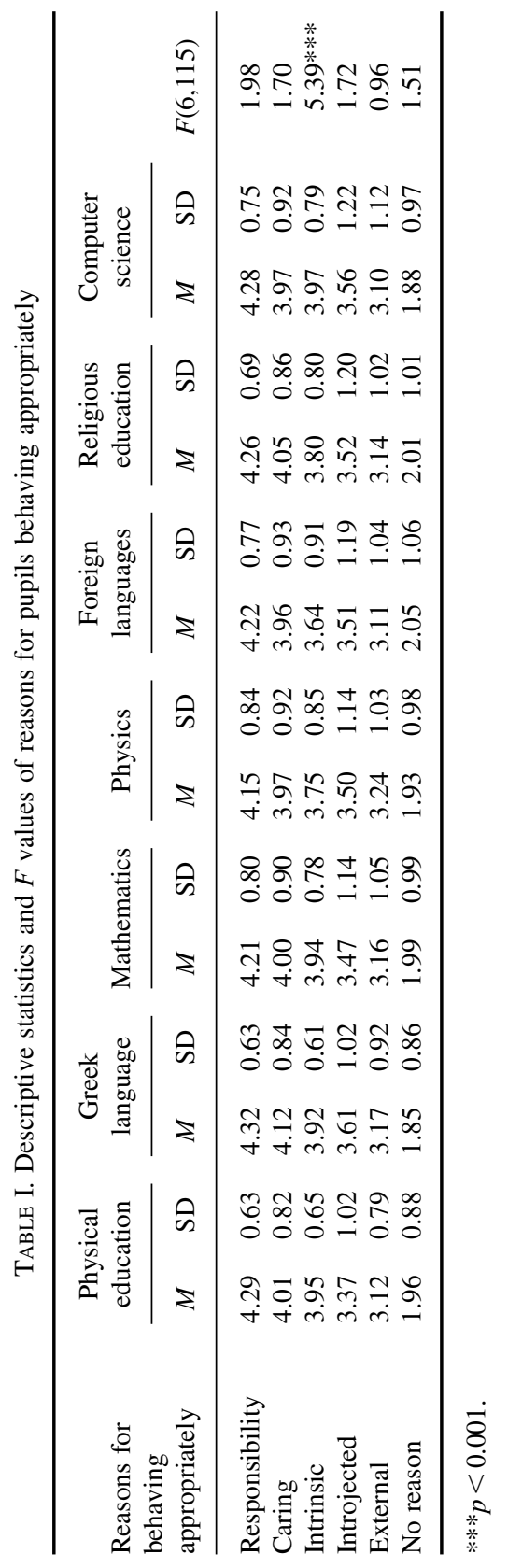


Responsibility $\square$ Caring $\square$ Intrinsic $\boldsymbol{\theta}$ Introjected $\square$ External $\square$ No reason

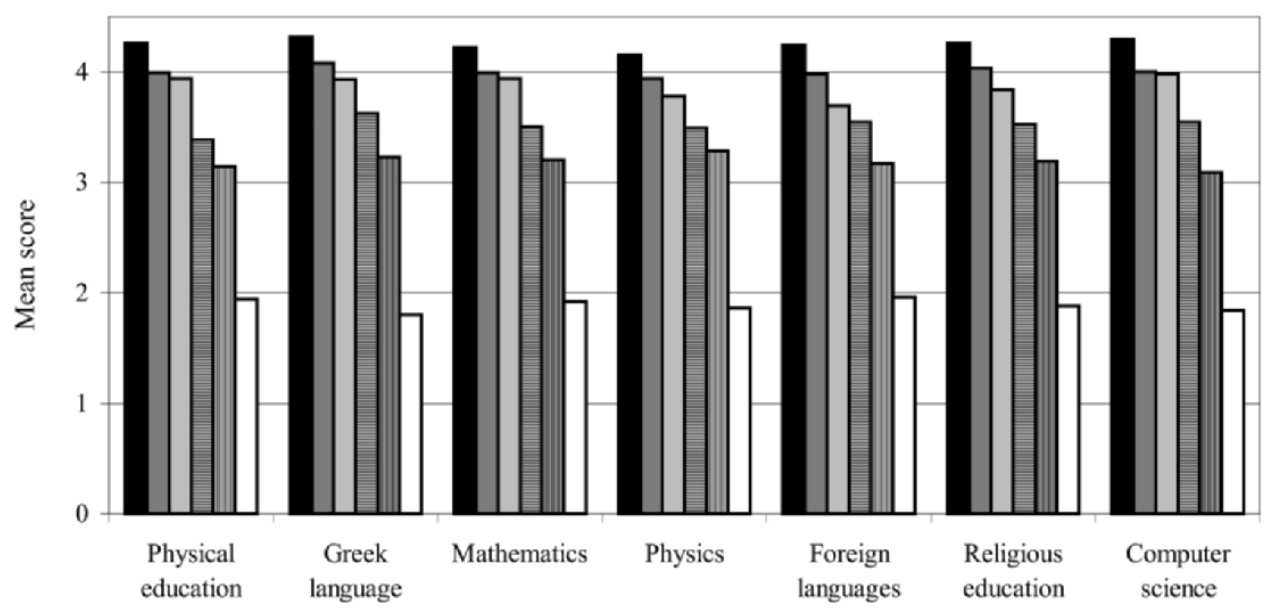

FIG. 1. Perceived reasons for pupils behaving appropriately.

significant difference was also found among several subjects of the curriculum on the strategies emphasising introjected reasons. $F(6,116)=4.88, p<0.001$. Using LSD pair wise comparisons, it was found that Greek language, physics and foreign languages teachers emphasise significantly more introjected reasons than do physical educators, teachers of computer science and teachers of religious education. Significant difference was found among several subjects of the curriculum on the strategies emphasising external reasons $F(6,116)=5.99, p<0.001$. Using LSD pair wise comparisons, it was found that Greek language teachers emphasise significantly more external reasons than do teachers of computer science, teachers of religious education and mathematicians. In the same strategy, statistically significant difference was also detected between physical educators and teachers of computer science, in favour of the physical educators. Finally, significant difference was found among several school subjects on pupils perception that their teacher does nothing to keep discipline $F(6,116)=2.79, p<0.05)$. Using LSD pair wise comparisons, it was found that pupils believe that their teachers of foreign languages and religious education are significantly less concerned with discipline than Greek language teachers, mathematicians and physical educators.

As shown in Figure 1, in all teaching subjects pupils are well-behaved firstly for responsibility reasons. That is, the pupils are well-behaved mainly because they want to be consistent to their selves and their beliefs. Secondly, the students are well-behaved because they believe that in this way they contribute to the progress of the whole class, so they help their classmates (caring reasons). Thirdly, in the present study, follow intrinsic reasons for behaving appropriately, and after that, introjected reasons. Fourthly, the pupils ascertain that they are disciplined because of external reasons. Finally, the pupils seem to disagree with the opinion that there is no reason for behaving appropriately. A repeated measures analysis of variance was performed to compare reasons for behaving appropriately in each subject of the curriculum. Using $F$ criterion, significant difference was found in all subjects $F(5,138)$, 


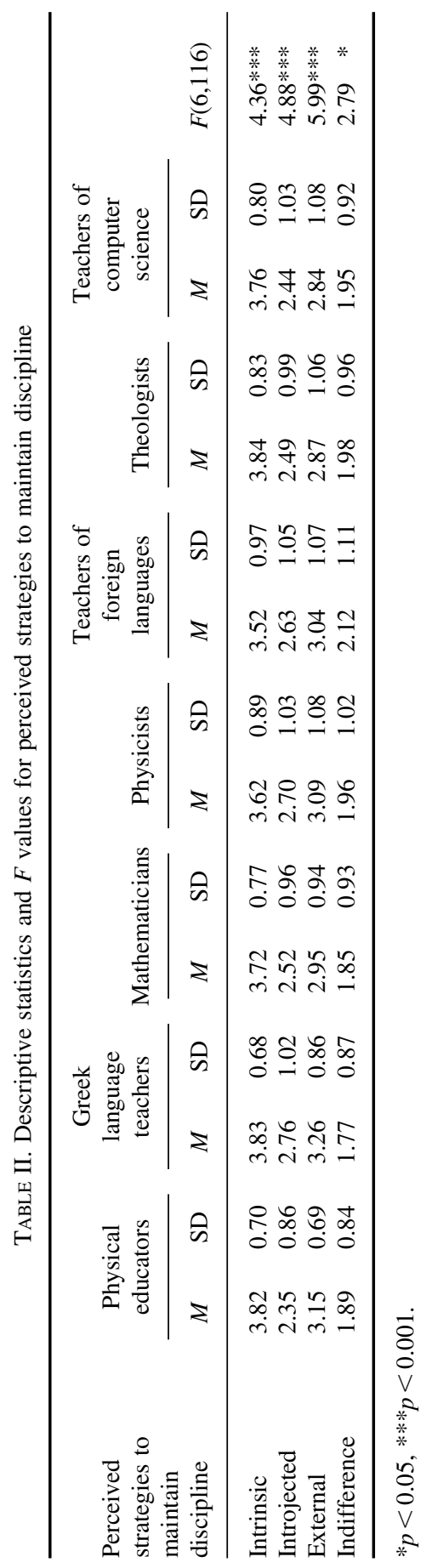




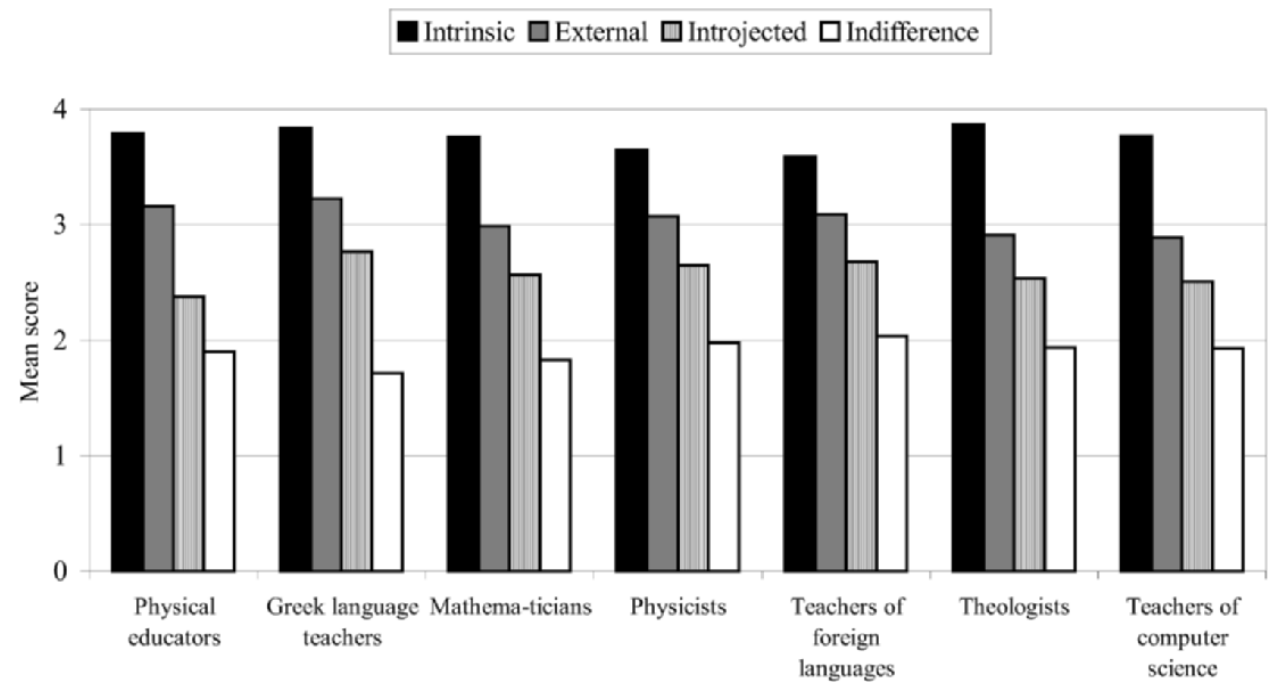

FIG. 2. Perceived strategies used by teachers to maintain discipline.

$p<0.001$. From the LSD pair wise comparisons, it was derived that in all pairs of the reasons, there exists a statistically significant difference.

As shown in Figure 2, in all subjects, teachers firstly use strategies that emphasise intrinsic reasons. Secondly, the pupils perceive that their teachers in all subjects use strategies emphasising external reasons of discipline. Thirdly, according to the pupils' opinion, the teachers use strategies emphasising introjected reasons, and finally the pupils consider that their teachers to a lesser degree use no strategy to maintain discipline. A repeated measures analysis of variance was performed to compare strategies to maintain discipline in each subject of the curriculum. Using $F$ criterion, significant difference was found in all subjects $F(3,144), p<0.001$. From the LSD pair wise comparisons, it was derived that in all pairs of strategies there exist statistically significant difference.

Pearson's correlations among the six reasons for behaving appropriately and four strategies used by teachers to maintain discipline for each school subject are presented in Table III. As shown by the values in italics in Table III, in all school subjects, strong positive relationships between pupils' reasons for behaving appropriately and the corresponding strategies used by teachers were found, apart from the relationship between pupils' introjected reasons for behaving appropriately and teaching strategies promoting introjected reasons. Concretely, correlations between strategies emphasising intrinsic reasons to maintain discipline and pupils' intrinsic, responsibility and caring reasons for behaving appropriately were above 0.324 $(p<0.001)$, in all school subjects. The correlations between the pupils' external reasons for behaving appropriately and teaching strategies promoting external reasons were above $0.398,(p<0.001)$. The correlations between pupils' amotivation (no reason) for behaving appropriately and teachers' indifference to maintain discipline were above 0.396, $(p<0.001)$.

The findings of the present study converge partially as to reasons for pupils behaving appropriately and as to the pupils' perceived strategies to maintain discipline with the results of Papaioannou (1998) and Spray (2001). In the studies of the earlier mentioned researchers, as well as in the present study, based on cognitive 


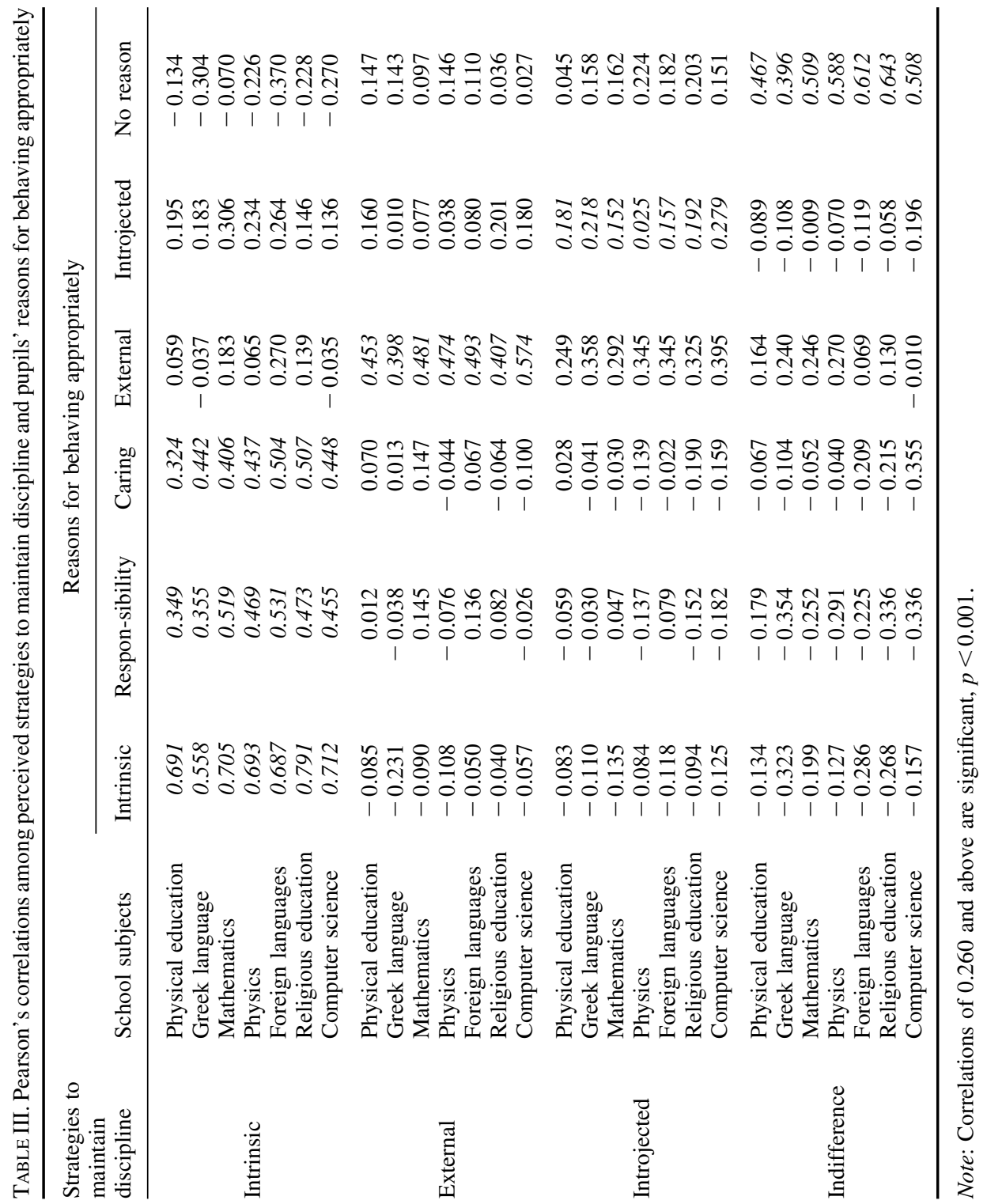


evaluation it was found that the pupils behave appropriately in class for self-determined reasons. The finding that the pupils want their teachers to emphasise the teaching strategies (intrinsic) that help them acquire responsibility in their behaviour was also confirmed. It is worth mentioning that the convergence of the results was confirmed for all school subjects we studied. Additionally, the findings of Millers' study (1995) have enough relevance to our findings. Miller found, besides other findings, that discipline is improved in the long run when the pupils adopt intrinsic motivation for their behaviour.

The present study established that in all school subjects there is a strong correlation between pupils' reasons for behaving appropriately and their perceptions about strategies used by teachers to maintain discipline. The strong positive correlations between strategies emphasising intrinsic reasons to maintain discipline and pupils' responsibility and caring reasons for behaving appropriately support the value of Hellison's responsibility model (1985). Similar results were found by Papaioannou (1998), who in addition, asserts that using teaching strategies emphasising intrinsic reasons, help pupils move from the level of irresponsibility to more acceptable levels of behaviour.

\section{Conclusions}

The problem addressed by this study was the reasons for pupils behaving appropriately in several subjects of curriculum and the perceived strategies used by their teachers to maintain discipline. The results support other recent research findings (e.g. Papaioannou, 1998; Spray, 2001) in indicating that reasons for pupils being well-behaved in class are self-determined. In computer science, physical education, mathematics and Greek language, pupils adopt significantly more self-determined reasons for behaving appropriately than in the remaining school subjects. This finding implies that the first group of subjects are more pleasant and enjoyable for pupils (e.g. 'The lesson is fun'), and at the same time these lessons offer more opportunities for positive pupil behaviour (e.g. 'I want to improve in the lesson'... ).

Despite the differences among several school subjects, in order to maintain discipline, teachers use teaching strategies that emphasise intrinsic reasons for good behaviour. The results of this study have practical value because they reveal to teachers that by promoting intrinsic motivation and self-determination in their pupils' behaviour they may succeed in increasing pupils' school performance. In fact, as Deci and Ryan (1994), after comprehensive review of laboratory experiments and field studies, concluded that the intrinsic motivation is positively associated with high quality learning.

Much research corroborated that the 'cooperative setting promotes intrinsic motivation in that it leads to less anxiety, greater task involvement and a more positive emotional tone than does competition' (Deci \& Ryan 1985, p. 258). Therefore in order to promote intrinsic motivation in schools, more cooperative and creative teaching methods should be used instead of competitive and reproductive methods. However, the promotion of intrinsic motivation is not an easy and quick process and does not depend only on teaching methods used by teachers. Family and social context also play a very important role in encouraging children to internalise the value of discipline and to be intrinsically motivated.

For further investigation of the problem, raised in this study, it is suggested pupils' perceptions for being well-behaved and strategies used by their teachers to sustain 
good behaviour be correlated with pupils' goal orientations, and perceived motivational climate, taking into consideration not only teachers' subjects, but also other characteristics of teachers such as their sex, experience, personal knowledge and personality components. It is also suggested to researchers in other countries that they undertake similar research in their countries, so as to investigate the issue of discipline in different educational systems.

Correspondence: Katerina Zounhia, National and Kapodistrian University of Athens, Department of Physical Education \& Sport Science, 41, Ethnikis Antistasis Street, 17237 Dafne, Athens, Greece. E-mail: azounhia@cc.uoa.gr

\section{NOTES}

[1] Reproductive educational system is one in which mainly teachers make all the decisions about the lesson. Pupils are not encouraged to take initiative.

[2] Authoritarian character of an educational system means that pupils' main concerns are grades, rewards, and fear of punishment rather than actual learning.

\section{REFERENCES}

Aravanis, G. (1998) Discipline in Education. The role of punishments and rewards in school and kindergarten (Athens, Publication Grigori).

CAFFYN, R. E. (1989) Attitudes of British secondary school teachers and pupils to rewards and punishments, Educational Research, 31(3), pp. 210-220. PsycINFO 1990-15790001.

DeCI, E. L. \& Ryan, R. M. (1985) Intrinsic Motivation and Self-determination in Human Behavior (New York, Plenum Press).

DECI, E. L. \& RYAN, R. M. (1991) A motivational approach to self: integration in personality, in: R. DiEnTSBIER (Ed.) Nebraska Symposium on Motivation, vol. 38. Perspectives on motivation (pp. 237288) (Lincoln, NE, University of Nebraska Press).

DecI, E. L. \& Ryan, R. M. (1994) Promoting self-determined education, Scandinavian Journal of Educational Research, 38(1), pp. 3-14.

ERB, M. (1996) Increasing Students' Responsibility for their Learning through Multiple Intelligence Activities and Cooperative Learning. Master's action research project (Saint Xavier University and IRI/Skylight). ERIC ED400947.

Graham, G. (1992) Teaching Children Physical Education (Champaign, IL, Human Kinetics).

Guernsey, M. A. \& PeARY, M. (1986) Classroom Management: Theory into Practice. Paper presented at the International Conference of the Council for Exceptional Children (New Orleans, LA, 31 March-1 April 1986). ERIC ED302874.

Harrison, J. M., Blakemore, C. L., Buck, M. M. \& Pellet, T. L. (1996) Instructional Strategies for Secondary School Physical Education (Madison, Brown and Benchmark Publishers).

Hellison, D. R. (1985) Goals and Strategies for Teaching Physical Education (Champaign, IL, Human Kinetics).

Hellison, D. R. (1995) Teaching Responsibility through Physical Activity (Champaign, IL, Human Kinetics).

Hellison, D. R. \& Templin, T. J. (1991) A Reflective Approach to Teaching Physical Education (Champaign, IL, Human Kinetics).

Henkel, S. A (1991) Teachers' conceptualization of pupil control in elementary school physical education, Research Quarterly for Exercise and Sport, 62(1), pp. 52-60.

KIRIDIS, A. (1999) Discipline at School (Athens, Gutenberg).

Lavay, B. W., French, R. \& Henderson, H. L. (1997) Positive Behavior Management Strategies for Physical Educators (Champaign, IL, Human Kinetics).

LU, S. (1997) Culture and compliance gaining in the classroom: a preliminary investigation of Chinese college teachers' use of behavior alteration techniques, Communication-Education, 46(1), pp. 10-28. PsycINFO 07750002. 
Matsagouras, I. (1988) Organisation and Management of School Class. Theory and Practice of Organizational Didactics (Athens, Publication Grigori).

Matsagouras, I (1999a) Theory of Instruction. The Personal Theory as Framework of Stochastic-critical Analysis (Athens, Gutenberg).

Matsagouras, I (1999b) School Classroom. Space. Group. Discipline. Method. (Athens, Publication Grigori).

McKinley, K. H. \& Merrit, M. (1985) Teacher Professional Identity and Job-leaving Inclination in Oklahoma. Paper presented at the 69th Annual Meeting of the American Educational Research Association (Chicago, IL, 31 March-4 April 1985). ERIC ED264190.

MieszalsKi, S. (1997) (O przymusie I dyscyplinie w klasie szkolnej) About Constraint and Discipline in School Classroom (Warsaw, WsiP).

Miller, A., Ferguson, E. \& Simpson, R.(1998) The perceived effectiveness of rewards and sanctions in primary schools: adding in the parental perspective, Educational Psychology, 18(1), pp. 55-64. PsycINFO 00443004.

MiLleR, C. A. (1995) Improving Motivation in Eighth Grade Students. Master' s research paper (Saint Xavier University). ERIC ED394099.

PAPAIOANNOU, A. (1998) Goal perspectives, reasons for behaving appropriately, and self- reported discipline in physical education lessons, Journal of Teaching in Physical Education, 17(4), pp. 421441.

Papaioannou, A., Theodorakis, Y. \& Goudas, M. (1999) For Better Instruction of Physical Education (Thessaloniki, Salto Publications).

PARKER, J. (1995) Secondary teachers' views of effective teaching in physical education, Journal of Teaching in Physical Education, 14, pp. 127-139.

PIERON, M. (1988) Enseignement des Activites Physiques et Sportives. Observations et Recherches ( Preeses Universitaires de Liege A.S.B.L).

PlaceK, J. H. \& DodDS, P. (1988) A critical incident study of preservice teachers' beliefs about teaching success and nonsuccess, Research Quarterly for Exercise \& Sport, 59(4), pp. 351-358.

Robertson, J. (1998) Effective Classroom Control (London, Hodder and Stoughton Limited).

Ryan, R. M. \& Conell, J. P. (1989) Perceived locus of causality and internalization: examining reasons for acting in two domains, Journal of Personality and Social Psychology, (57)5, pp. 749-761.

SiEdEnTOP, D. (1995) Use positive discipline for middle school student, Strategies, 8(8), pp. 5-8.

SPRAY, C. (2001) Pupils' goal perspectives and the internalization of reasons for disciplined behavior in physical education lessons, in: A. Papaioannou, M. Goudas \& Y. TheodoraKis (Eds) 10th World Congress of Sport Psychology (Skiathos Hellas, 28 May-2 June 2001, Program and Proceedings, 4, pp. 346-348).

Tulley, M. \& ChIU, L. H. (1998) Children's perceptions of the effectiveness of classroom discipline techniques, Journal of Instructional Psychology, 25(3), pp. 189-197. PsycINFO 03423004.

Wan, F. \& SALILI, F. (1996) Perceived effectiveness of reward and punishment strategies by Hong Kong secondary school students, Psychologia: An International Journal of Psychology in the Orient, 39(4), pp. 261-275. PsycINFO 1997-07505007. 
Appendix

TABLE AI. Reasons for discipline scale

When I am well-behaved in class,

it is because ...

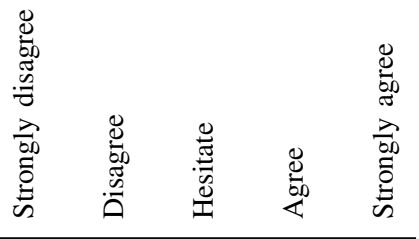

... That's what I am supposed to do

... So that the teacher won't yell at me

... That's the rule

... So others won't get nervous with me

... I will feel bad about myself if I don't

... I will feel ashamed if I don't

... It bothers me when I don't

... I want to follow the lesson

... I want to learn new skills

... To understand where I am right or wrong

... It's important for me to do well in the

lesson....

... I want to be improved in the lesson....

... The lesson is fun

... I enjoy the lesson

... The lesson of.... is exciting

... I really don't know why I am disciplined

... I don't see why I should be disciplined

... I really feel that I lose time by being disciplined in the lesson

... I try to be a responsible person

... I feel that I am responsible for what I learn

... I try to be consistent with myself and the others

... I want to be consistent with what I say and what I do

... I want my schoolmates to understand what they are doing

right or wrong

... I like all the class to progress

... It's important for me everybody in the class to improve

Source: Papaioannou, 1998.

Thank you for your time. 
TABLE AII. Strategies to sustain discipline scale

In this class in order to sustain the teacher of

$$
\text { discipline }
$$

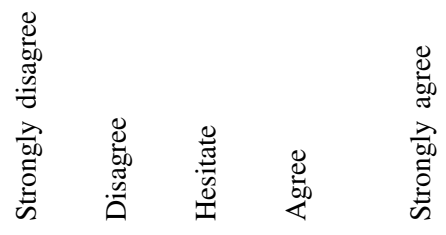

... Threatens that we'll get in trouble if we misbehave

... Reminds us that we are supposed to be well-behaved

... Yells at those who are not well-behaved

... Reminds us that it is the rule

... Makes us feel bad about ourselves if we are not well-

behaved

... Makes us feel ashamed if we are not well-behaved

... Reminds that only those who are well-behaved are considered good students

... Makes us fell uncomfortable when we are not wellbehaved

... Attracts our attention by making the lesson more interesting

... Makes the lesson in such a way that we attend to understand what we are doing wrong and what right

... Attracts our attention because s/he makes us to believe that it is important to do well in the lesson.

... Attracts our attention because s/he makes us to improve

... Makes the lesson. funny

... Makes us enjoy the lesson.

... Makes the lesson. exciting

... Really does nothing to keep discipline

... I don't see him (or her) interested in the discipline of the class

... I really feel that there is no discipline at all in this class

... Helps us become responsible of our actions

... Helps us in such a way that in the end what we do is what we say

... Helps us to become responsible for our progress

... Helps us to understand the others

... Encourages cooperation and mutual understanding

... Makes us learn how to teach one another

... Makes us love the progress of our schoolmates

Source: Papaioannou, 1998.

Thank you for your time. 

Copyright $\odot 2003$ EBSCO Publishing 